\title{
Variants management and extended enterprise models for the car maker's factory of the future
}

\author{
Prof. Dr. J. Borda Elejabarrieta C.E.O.; of Sisteplant, S.A. \\ Professor of Production and Engineering Management at \\ Deusto University and Member of I.F.I.P. WG 5.7. \\ Parque Tecnológico Edificio 10548170 ZAMUDIO Spain \\ Phone: (34) 44520611 Fax. (34) 44521266 \\ E-mail: datalde@redestb.es \\ http: //www.Sisteplant.com
}

\begin{abstract}
In the future of the car industry, variants management are one of the keys. Much more short delivery of cars will lead to a strategic split of the variants generation in distributors, suppliers and local "compact" plants. A very rapid and synchronized on-line configuration of modularized sub-assemblies will be performed in these new generation assembly compact plants.
\end{abstract}

\section{INTRODUCTION AND BACKGROUND}

The Car maker's factory of the future is going to be a main mixed model and integrated non-stop line from body shop to final assembly, and low vertical integration is going to be a trend. High velocity in the development of technologies involved in the car make this last an irreversible fact (see Figure 1). To prevent line breakdowns effects in the really scarce case they go on, robots and other general purpose assembly devices will clamp and unclamp continuously to the "non-stop line" carrying the car, thus giving also great flexibility in self balancing the mixed model flow. 

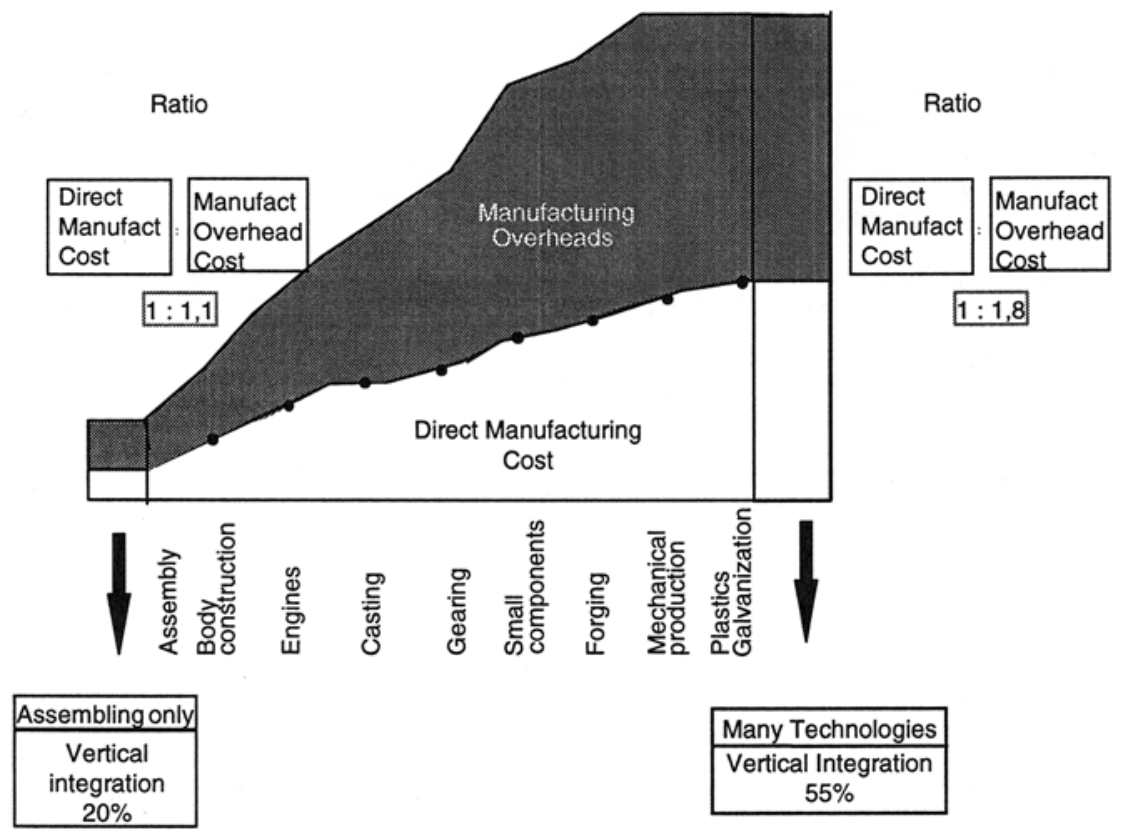

Figure 1: The effects of decreasing vertical integration in the car industry

This production model will involve a very low ratio of man power assembly hours per car, deploying at the same time the possibility of one-unit lot, and also protection against process obsolescence due to product changes, then optimising the contradictory poles of mechanical integration, polyvalence and flexibility at a high automation rate (Figure 2).

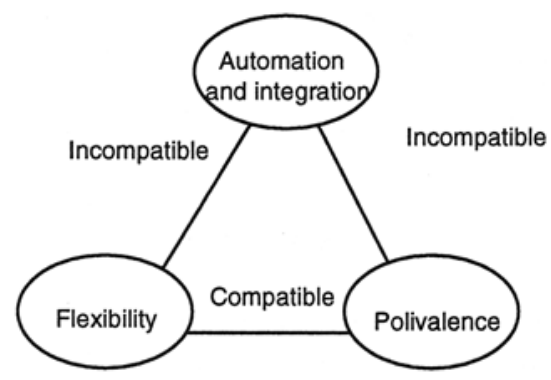

Figure 2: The manufacturing strategy poles. The challenge is to make compatible a flexible polivalent system with an automated integrated one. 
The auxiliary lines, that feed the main line, will consist of synchronised cassettes of high integrated sub-assemblies (examples are the cockpit, seats, entire doors and roofs-laser welded, wheels, exhaust-systems, frontals and backs, etc.). Looking at the entire doors means "painted and dressed". Given that getting identical painting when different batches is a problem, local mini-painting cabs set in these auxiliarylines will perform lot size $=1$. This JIT painting based on the real-time RAL monitoring of the main-line body paint result, and the correspondent set-point in the mini-cab special devices for rapid post-painting assembly of the dressing will be developed. The possibility of plastic reinforced (SMC or special thermoplastics) doors is difficult because lot size of 1 is not practically achievable today in mouldings.

In the case of non-excessive complexity and required lay-out volume, sub assemblies will be produced (and not only stored and handled) in these local front-end auxiliary lines, and will be run by selected suppliers. Looking at the Figure 3, type 1 and 2 of suppliers are candidates to front-end local assembly, and specially for the type 2 could be the unique strategy, giving that they are involved with subassemblies that have great capability of future product differentiation, and then they are a part of the car maker's know-how very strict protection.

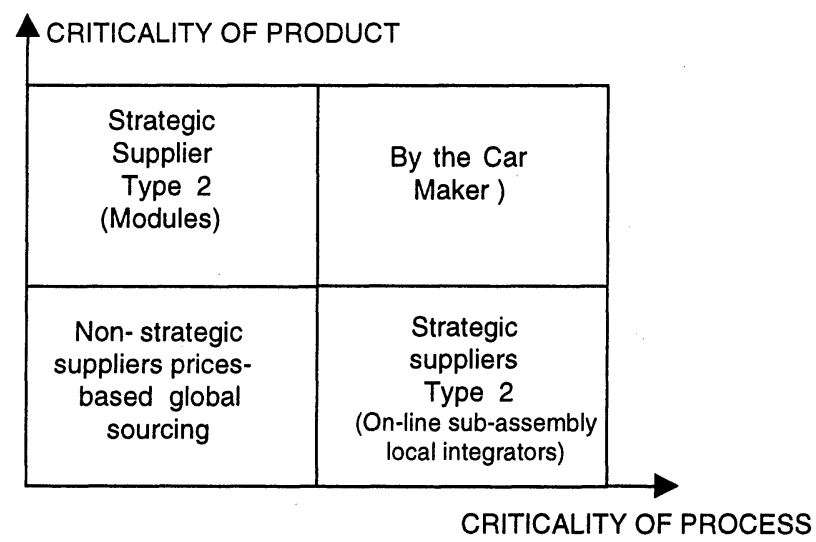

Figure 3: The selected supplier's matrix. The criticality is synonymous of the ability to differentiate in the future by both product or process design.

On the other hand, and depending upon process complexity and space needed, Type 1 suppliers can be or not part of the integrated auxiliary lines. Other important issue concerning type 1 and 2 strategic suppliers is, from the car- maker's point of view, the increasing preference of medium-sized companies, agile, and with customised product or process technology development capabilities and enough financial supports. This is going to be a significative change in the next years. 
Such a manufacturing model needs "Design for logistics" as a primary issue; one would say that "logistic strategy leads to manufacturing strategy", and that the "minimum transfer-batch" is the next objective for the "current production batch". And in "Design for logistics", variants management is one of the keys.

The new generation of car assembly plants are going to perform on-line configuration of unitary lot-size, based on a product design prepared for modular local subassemblies. In on-line modular configuration, product-design for achieving variants with as much single items as possible is a strong issue.

The customization by markets in one clear trend, and this leads to have more and nearer sites for variants configuration. Huge multi-regional and single-model plants are going to be changed by small local compact mixed-model facilities, serving distributors.

In order to go on with simplicity enough, variants generation has to be split:

a) The final distributor will customize the car in terms of for instance wheels, lighting options and software, and in general not very voluminous subassemblies that can be easily and economically end-term assembled and also shelved there by suppliers.

b) The strategic suppliers of type 2 (see Figure 3 ) are not going to be integrated around the main line in the "compact" plant, which is, not any other consideration set, more interesting for them. But they have to carry on with modular development fit to the car-maker strategy, and in consequence, some scaleeconomy is lost.

The main line concept in the compact-plant is given esquematically in Figure 4. There, to save in space with an increased area of sub-assembly operator, the lay-out is set in a way that auxiliary lines for on-line configuration of sub-assemblies from modules, are nested in each sine and also present 3D material handling capabilities.

The main line gives electronic signals to the auxiliary lines for timed on-line synchronisation. In this mixed-model lot-size $=1$ main line, body construction flexibility is essential. Let's have a look at the management of this point.

A clear example in the Auto industry is the jig system for the body frame construction so called BIW; ("body in white"). Making a versatile reconfigurable jig gives both flexibility and polyvalence at the same time, and no so much investment with the condition of designing appropriated model's frames ready to be welded along with the same adjustable jig. Another example of DFA for the auto industry is the JIT supply of complete sub-assemblies to the main line. Assembling by a robot the entire cockpit, transmissions, the frontal panel, or seats are clear aspects of DFA applied after a tuned logistics and supplier development strategy. If the frame jigs are prepared for mixed model main lines, you will find not less difficult the subassembly feeding systems (cassettes, ramps, and so on) for also different models. 
Main line tooling is generally hard tooled-multi-welders or form fixtures, that will only process a particular component or model. A good example of this is the framing operation in the body construction process, where the main body subassemblies are put together to form the body-in-white (BIW), or complete steel structure of or car.

The framing station consists of a hard tooled multi-welder, and clamping configuration and this operation provides the dimensional integrity of the BIW by giving the sub-assemblies in the correct position by the minimum number of spots for this purpose. The remaining spot welds are made by a series of robots after the framing station. The tooling for the framing is very complex and it is considered that such tooling is unlikely to be truly flexible.

One way to achieve flexibility is to use robots in those areas that have historically been limited to hard tooling and multi-welders, like framing. Robots provide great advantages due to re-programmability, and suitability for a wide range of tasks from welding to part handling, but many limitations exists for the use of robots. First physical limitations of load capacity and speed, and second in terms of capacity given that robots can only produce one spot weld at a time, compared to a multiwelder that can produce any number of spot welds simultaneously. To address this problem more than one robot is generally used, but when compared to the investment requirements for hard tooling this may be an unsuitable option.

One case is interesting to be reviewed; the body construction of Toyota. The assembly line is a highly automated production system capable of producing a large number of car models, with the ability to change model production without significative set-up. The development of the system was based on a number of basic concepts such as measures to improve body accuracy, measures to ensure flexibility, measures to enhance efficiency and streamline production management, measures to simplify the preparatory operation and reduce lead-time.

Body accuracy is improved firstly by restricting the number of spots welds made on the sub assemblies until they reached the final assembly line, where they were fixed with the desired accuracy by applying sufficient welds. Secondly, through the use of a fixture circulation system, that moves fixtures through the assembly processes thus reducing the stack up of tolerances of the sequential assembly processes, when components are moved from one fixture to the next. To ensure flexibility only the circulating fixtures for the underbody, bodysides, roof, and lower back were made model-dependent, and included onto pallets that could carry them around. Hard automation was replaced with robots where ever possible, and for improving efficiency the number of processes was minimised by using a large number of robots in each process and by reducing the part handling processes. This also reduces the variation in the body accuracy by 50\%, resulting in a great improvement in quality.

To smooth a.m.a.p. load in the auxiliary lines, sequencing of cars are performed by an algorithm such as the "Goal-chasing" method giving, in a time-window frame, the most convenient order in which the cars lot size 1 are going to be assembled with the most regular comsuption of sub-assemblies along the auxiliary-lines. 
The manufacturing strategy in the auxiliary-lines is lead by flexibility and time for pre-assemblies. Assuming lot - size $=1$, in the worst condition, the time for changeover plus the time for pre-assembling one code has to be less than the time between two consecutive cars.

Of course, configuration in these areas is going to be of just "one-level" of operation, assuming also just "one-level" assembly operation in these areas, conforming it in "one-stroke" from the shelves. "Pater-noster" alike material handling systems are in the middle of the area.

In reference to the Figure 2 , once flexibility and velocity have been assured in a compact space, the trade off between polivalence and the degree of automation decides the final shape of the line.

The transfer between the main and auxiliary lines is given by clamping and unclamping stations in which the cassettes are pushed in level 1 (lower) until consumption, and removed from level 2 (upper) when exhausted from the main line. The stations will have a general purpose six or more d.o.f. robots and also more specific assembly devices.

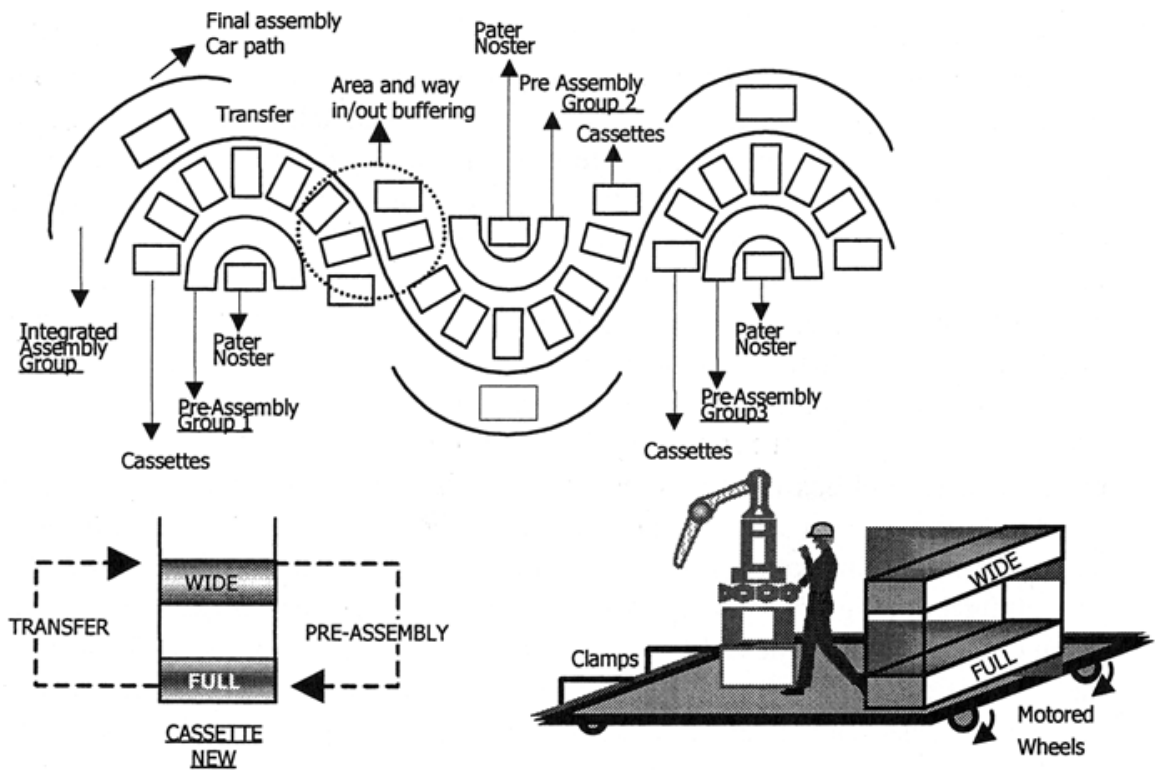

Figure 4: The new assembly concept of car-maker local compact-plant The " $U$ " shape allows integration of pre-assembly and assembly 


\section{THE COST-MODEL FOR VARIANTS MANAGEMENT}

Variants strategy is defined in the chapter two of this paper. The striking force is local configuration of modules in compact-plants, given the future regional customization of cars. But some kind of contrast is necessary to be done in order not to remove previous defined strategy, but to adjust it in terms of the number of variants offered in a given market and to orientate and push direct and indirect cost reduction.

A suitable way to do that is structuring the variants in terms of their nature and quantity and distribute them by appropriated cost-drivers.

Variants can be structured as follows:

Type 0: Body (e.g. solar roof)

Type 1: Engines

Type 2: Transmissions

Type 3: Interiors

Type 4: Specific package options

Type 5: Colours

Type 6: Wheels

Type 7: Lighting

Type 8: Software

Cost drivers have to be simulated for each one of these types, and for the following concepts, in an appropriated matrix.

- Direct manufacturing costs

- Changeovers

- Moulds, dies, fixtures and jigs

- Automation inhibition

- Scrap

- Purchasing prices (higher by less volume)

- Product and process engineering overheads

- $\mathrm{R}+\mathrm{D}$ product evaluation

- Product and process maintenance efforts

- EDP
- Transportation

- Long haul

- Short haul
- Asset Investments

- Machinery

- Handling devices

- EDP

The trade-off is given by Figure 5, and Figure 6 is a simple matrix performable in an electronic-sheet to simulate different alternatives. The modular concept of product is the response to increase variants changing the shape of the total complexity cost curve in the Figure 6. 


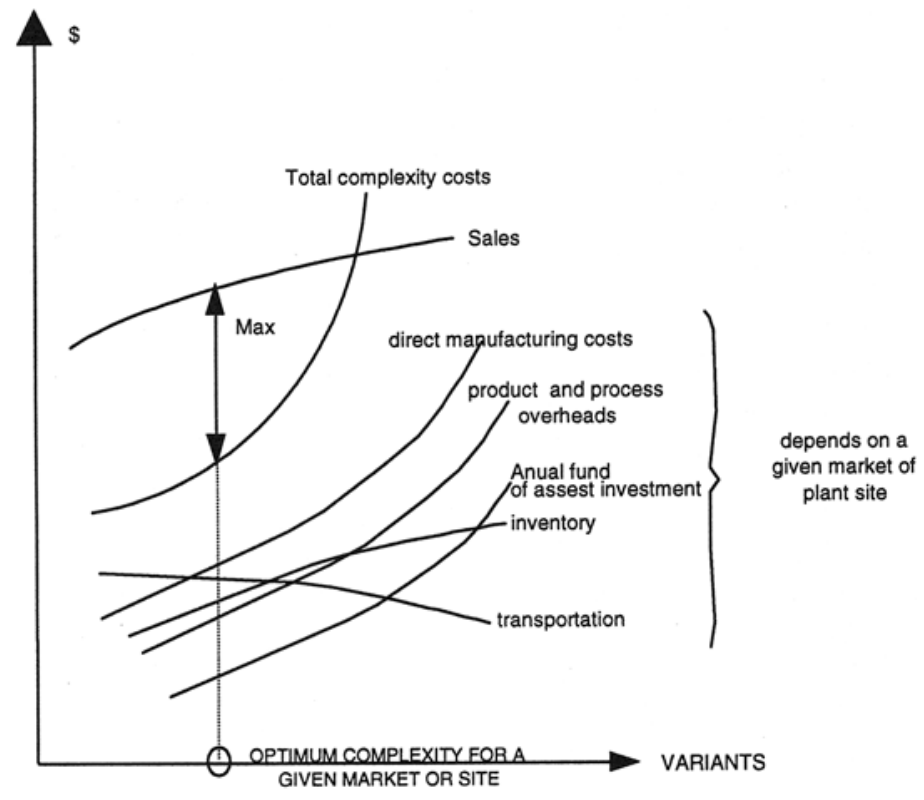

Figure 5: Complexity cost over sales lost

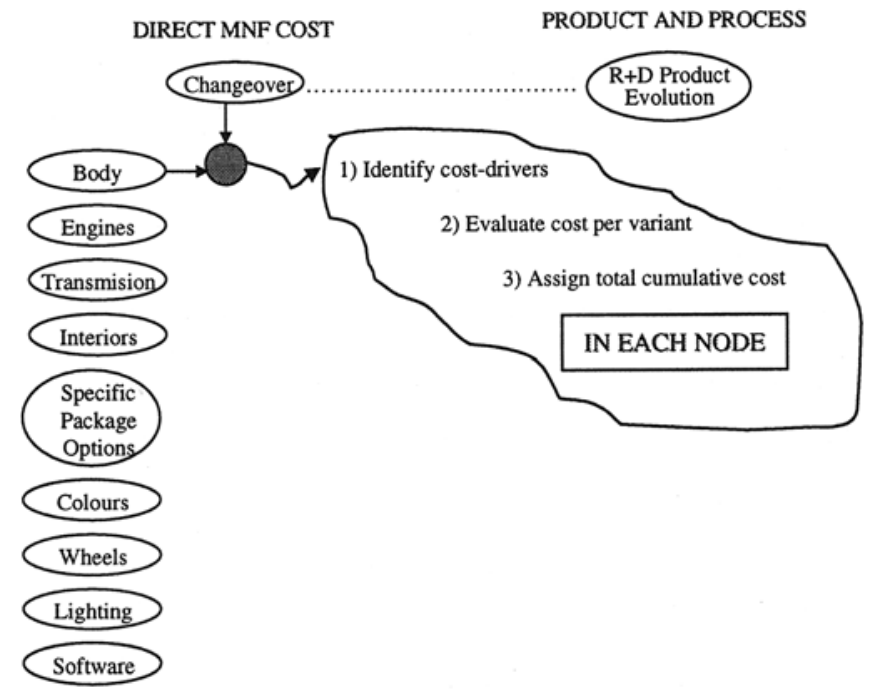

Figure 6: Matrix for simulating cost of variants 


\section{CONCLUSIONS}

Variants management will play a key role facilitating the manufacturing strategy of the car-maker, forced to fight with regional differences, very short delivery times, short life cycles and a furious competence in prices. Two levels of strategic suppliers have to be managed and distributor's role in car customization set up in order to create the "local compact plant" in which lot size of one is performed. Costing variants is the way to precise and adjust local product offer as well as simultaneously push direct and indirect cost reduction.

\section{BIOGRAPHY}

Prof. Dr. Javier Borda Elejabarrieta has been working as plant Engineer and Production Manager staff for 10 years, and from 1984 he is the managing director and C.E.O. of SISTEPLANT, S.A., a Spanish 50 people industrial engineering company, sited in the Basque Country and shared by the IBV Group, involved in entire subassemblies design and manufacture for the aerospace and automotive industry. He read in 1989 the Doctoral Mechanical Engineering dissertation on "CIM for plastic injection workshops". He is also Professor of Production and Engineering Management in the University of Deusto, Bilbao, and the author of several international papers and two books titled: "Advanced Maintenance Techniques" (1990) and "Vibrations Technology in Predictive Maintenance" (1998). He has become recently an IFIP WG 5.7 member. 